\title{
Thermal conformability of developed fibrous wound dressings
}

\begin{abstract}
A novel concept, based on collagen boosting agent treatment, has been explored in this study, wherein the developed nonwoven structures were treated with two different collagen promoting agents Vitamin $\mathrm{C}$ and zinc oxide $(\mathrm{ZnO})$ at $0.5 \%$ and $3 \%$ levels by using a spray method. With the rapid demand of modern and smart wound dressings, it is vital that an effort has to be made to develop novel wound dressings by making use of known collagen promoting agents to enhance wound healing especially cavity and difficult-to-heal wounds. It is in this context, an attempt was made to design and develop novel 'all-in-one' collagen-booster therapeutic nonwoven wound dressings. A significant contribution in this paper is that a CMC/PLA containing hybrid structure has been developed for the first time. The collagen booster loaded structures are fully characterised and evaluated in terms of thermal comfort properties.
\end{abstract}

Volume 2 Issue I - 2017

\author{
Muhammet Uzun, ${ }^{1,2}$ Subhash C Anand, ${ }^{3}$ Tahir \\ Shah ${ }^{3}$ \\ 'Faculty of Technology, Marmara University, Turkey \\ ${ }^{2}$ RWTH Aachen University, Germany \\ ${ }^{3}$ University of Bolton, UK
}

\begin{abstract}
Correspondence: Muhammet Uzun, Faculty of Technology, Marmara University, Istanbul, 34722, Turkey, Tel 9053645 I 9462 ,
\end{abstract} Email m.uzun@marmara.edu.tr

Received: March 02, 2017 | Published: June 07, 2017

Keywords: thermal comfort, collagen, wound dressing, PLA, CMC, water vapour permeability

\section{Introduction}

\section{Thermo physiological comfort testing}

Alambeta: The thermo physiological properties of the nonwoven fabrics were determined by using the Alambeta and Permetest instruments (Sensora Instruments, Czech Republic). The Alambeta instrument provides values for thermal conductivity, thermal resistance (insulation), thermal absorptivity (warmth-to-touch), fabric thickness and thermal diffusivity as shown in Figure 1. The test instrument was used to analyse the transient and steady state thermo physical properties of the fabrics. The specimens of $20 \mathrm{~cm} \times 20 \mathrm{~cm}$ were prepared and placed in between two plates. With the two plates the heat flow through the fabric due to the different temperature of the bottom measuring plate (at ambient temperature) and the top measuring plate which is heated to $40^{\circ} \mathrm{C}$. The thermal absorptivity of the textile structure is a measure of the amount of heat conducted away from structure's surface per unit time (1). The test was performed on the dry and wet states of the nonwoven fabrics which were wetted with $0.2 \mathrm{ml}$ of distilled water in the centre of the fabrics and allowed 4 minutes before retesting, in order to allow for the thermal recovery of the fabric. All the tests were carried out on both faces of each specimen and the mean values were calculated. ${ }^{1,2}$

Permatest: The water vapour permeability and the resistance to evaporative heat loss of the fabrics were tested by using the Permetest Instrument, Sensora Instruments, and Czech Republic in Figure 2. This instrument is based on the skin model, which simulates dry and wet human skin surface in terms of its moisture, water vapour and evaporative heat permeation. The instrument uses the same principle as specified in ISO 11092 developed by Hohenstein Institute, whereby a heated porous membrane is used to simulate the sweating skin. The heat required for the water to evaporate from the membrane, with and without a fabric covering, is measured (1). A heated porous membrane is used to simulate sweating skin. A current of air removes the micro-climate that develops above the surface of the membrane. The heat required evaporating the water from the membrane with and without a test fabric covering is measured. The fabric produces resistance to evaporation and therefore less heat is required. The results are used to calculate the relative water vapour permeability as a percentage of the control test without the fabric covering, and the resistance to evaporative heat loss in $\mathrm{m}^{2} \mathrm{PaW}^{-1}$. The specimens that were used for measuring the thermal properties in the Alambeta instrument were also used for testing on the Permatest apparatus.

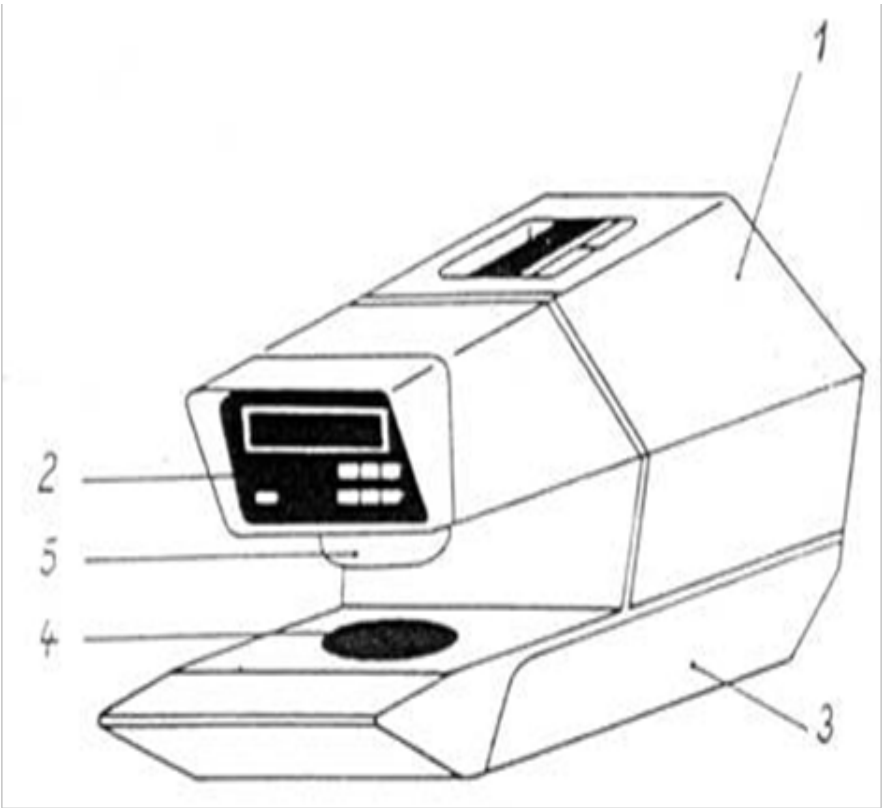

Figure I Alambeta Instrument by Sensora, Czech Republic; (I) control and evaluation unit; (2) control panel with display; (3) frame and housing unit; (4) measuring plate; (5) measuring head. 


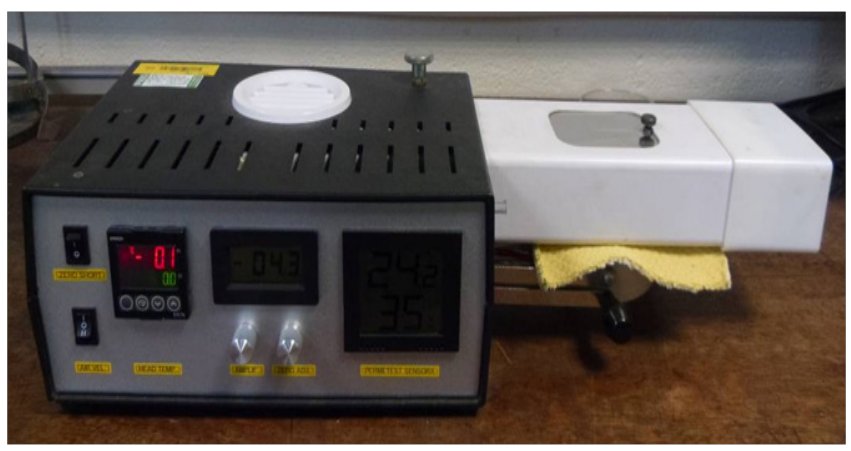

Figure $\mathbf{2}$ Sensora Permatest water vapour permeability apparatus.

\section{Results and discussion}

\section{Flexural rigidity and air permeability}

The flexural rigidity and air-permeability values of the fabrics are given in Table 1. It is apparent from this table that the flexural rigidity and air-permeability properties of the fabrics were not affected by the treatment process as well as the collagen booster ratios or types. It is clearly demonstrated that both the flexural rigidity and the airpermeability properties depend on the fabric area density and fibre types present in the structure. This study has produced the results which are more or less similar to the previous study. The HPES fibres containing fabrics had the lowest flexural rigidity values compared to the other fabrics tested. It was also found that the untreated PLA reinforced CMC composite fabrics had considerably lower flexural rigidity values than single-fibre CMC fabric. It is well-known that a lower flexural rigidity gives higher conformability, softness and flexibility to the wound dressing. It can thus be concluded that the flexural rigidity properties of CMC fabrics can be enhanced by using PLA or HPES fibres. This enhancement can have a positive effect on the conformability properties of the dressings, which could directly affect the wound healing process.

The air permeability is a quantitative measurement of how well a material allows the passage of air through it. It can be defined the volume of air in $\mathrm{mm}^{3}$ which is passed through the dressing in one second from $100 \mathrm{~mm}^{2}$ of the fabric at a pressure of $10 \mathrm{~mm}$ head of water. The air permeability is one of the important parameters of wound dressings, which prevents maceration and (2) gives a better comfort to the patients. In a recent in vivo study on wound healing and antibacterial performance of electrospun nano fibre membranes, the authors concluded that the porosity and air permeability characteristics have a strong influence on facilitating the wound healing, especially at the early healing stages (3). It can also be noticed from the data in Table 1 that the air-permeability values of the fabrics increased when the fabrics' area densities decreased. Another important finding was that the air-permeability of the reinforced fabrics was found to be greater than the single-fibre CMC fabrics. The HPES fibres reinforced fabrics had higher air-permeability as compared to all other fabrics tested due to its hollow structure. One of the important properties for a wound dressing is its air-permeability, which helps in preventing maceration and providing better comfort to the patients (4). ${ }^{3}$

\section{Thermo physiological comfort}

The present test was designed to determine the effect of the treatments on the fabrics' thermo physiological comfort properties.
Table I Flexural rigidity and air-permeability values of treated fabrics

\begin{tabular}{lll}
\hline Fabrics & $\begin{array}{l}\text { Flexural rigidity } \\
(\boldsymbol{\mu N m})\end{array}$ & $\begin{array}{l}\text { Air } \\
\text { permeability } \\
\left(\mathbf{c m}^{3} \mathbf{s e c}^{-1}\right)\end{array}$ \\
\hline $100 \%$ CMC untreated & 320 & 350 \\
$100 \%$ CMC 0.5\% VC & 125 & 612 \\
$100 \%$ CMC 3\%VC & 130 & 509 \\
$100 \%$ CMC 0.5\% ZnO & 115 & 713 \\
$100 \%$ CMC 3\% ZnO & 142 & 491 \\
$75 / 25 \%$ CMC/PLA untreated & 243 & 412 \\
$75 / 25 \%$ CMC/PLA 0.5\% VC & 162 & 689 \\
$75 / 25 \%$ CMC/PLA 3\%VC & 171 & 591 \\
$75 / 25 \%$ CMC/PLA 0.5\% ZnO & 196 & 601 \\
$75 / 25 \%$ CMC/PLA 3\% ZnO & 180 & 655 \\
$75 / 25 \%$ CMC/HPES untreated & 230 & 489 \\
$75 / 25 \%$ CMC/HPES 0.5\%VC & 105 & 897 \\
$75 / 25 \%$ CMC/HPES 3\%VC & 111 & 915 \\
$75 / 25 \%$ CMC/HPES 0.5\% ZnO & 122 & 908 \\
$75 / 25 \%$ CMC/HPES 3\% ZnO & 145 & 70 \\
\hline
\end{tabular}

\section{Thermal resistance of nonwoven fabrics in dry and} wet state

The thermal resistance and \% recovery values of the fabrics tested after 4 minutes of wetting the fabric are given in Table 2 . The thermal resistance of the fabrics ranged from 99 to $142 \mathrm{~W}^{-1} \mathrm{~K} \mathrm{~m}^{2} \times 10^{-3}$ for the dry state and from 68 to $114 \mathrm{~W}^{-1} \mathrm{~K} \mathrm{~m}^{2} \times 10^{-3}$ for the wet state. The thermal resistance values of the fabrics decreased significantly in the wet state. The difference between the untreated single-fibre CMC fabric and PLA or HPES fibres reinforced fabrics was considered to be worth mentioning. The thermal resistance properties of the single-fibre CMC fabrics were increased significantly due to the vitamin $\mathrm{C}$ and $\mathrm{ZnO}$ treatment. On the other hand, the thermal resistance properties of the PLA or HPES fibres containing fabrics decreased after the treatment. It can be suggested that the treated composite fabrics can have better comfort properties because of its relatively lower thermal resistance value. In most of the cases, the \% recovery of the treated fabrics was found to be lower than their untreated counterparts. ${ }^{2}$

\section{Thermal absorptivity of nonwoven fabrics in dry and wet state}

The thermal absorptivity results are presented in Table 3. The results of this study show that the thermal absorptivity values of the fabrics were affected by the fibre and the treatment types. The singlefibre $\mathrm{CMC}$ fabric had higher thermal absorptivity than CMC/PLA and CMC/HPES fabrics. It was also found that the treated fabrics had lower absorptivity than their untreated counterparts. The differences between the untreated and treated fabrics were found to be significant. There is no observed difference between vitamin $\mathrm{C}$ and $\mathrm{ZnO}$ treatment neither for the ratio of $0.5 \%$ nor for the ratio of $3 \%$. Table 3 also shows that the thermal absorptivity of fabrics in the wet state generally was found to be higher than the thermal absorptivity of fabrics in the dry state. 
Thermal conductivity of nonwoven fabrics in dry and wet state

Table 4 gives the thermal conductivity results. The thermal conductivity of the treated fabrics was lower than their untreated counterparts. It is somewhat surprising that $\mathrm{ZnO}$ treated fabrics also had decreased thermal conductivity. It was expected that the $\mathrm{ZnO}$ treatment would increase the thermal conductivity due to its conductive nature. In a previous study by the author, it was determined that silver treatment increases the thermal conductivity of the single-fibre CMC nonwoven fabrics. This study confirms that the thermal conductivity of fabrics in the wet state were significantly higher than in the dry state. This is obvious, as the water is a good conductor of heat. ${ }^{2}$

Table 2 Thermal resistance $(r)$ properties of treated fabrics

\begin{tabular}{|c|c|c|c|}
\hline \multirow[t]{2}{*}{ Fabrics } & \multirow{2}{*}{$\begin{array}{l}\text { Dry } \\
\left(\mathrm{W}^{-1} \mathrm{Km}^{2} \times 10^{-3}\right)\end{array}$} & \multirow{2}{*}{\multicolumn{2}{|c|}{ 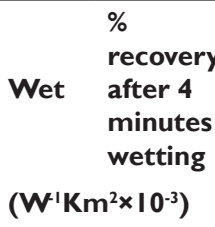 }} \\
\hline & & & \\
\hline $100 \%$ CMC untreated & 115 & 101 & 86.1 \\
\hline $100 \%$ CMC 0.5\% VC & 142 & 100 & 58 \\
\hline $100 \%$ CMC 3\% VC & 130 & 80 & 37.5 \\
\hline $100 \%$ CMC $0.5 \% \mathrm{ZnO}$ & 135 & 110 & 77.3 \\
\hline $100 \%$ CMC 3\% ZnO & 121 & 75 & 38.7 \\
\hline $75 / 25 \%$ CMC/PLA untreated & 123 & 95 & 70.5 \\
\hline 75/25\% CMC/PLA 0.5\% VC & 99 & 73 & 64.4 \\
\hline $75 / 25 \%$ CMC/PLA 3\% VC & 107 & 68 & 42.6 \\
\hline 75/25\% CMC/PLA 0.5\% ZnO & $|3|$ & 114 & 85.1 \\
\hline 75/25\% CMC/PLA 3\% ZnO & 107 & 87 & 77 \\
\hline 75/25\% CMC/HPES untreated & 137 & 110 & 75.5 \\
\hline 75/25\% CMC/HPES 0.5\% VC & 107 & 78 & 62.8 \\
\hline 75/25\% CMC/HPES 3\%VC & 99 & 78 & 73.1 \\
\hline 75/25\% CMC/HPES 0.5\% ZnO & 129 & 101 & 72.3 \\
\hline 75/25\% CMC/HPES 3\% ZnO & 108 & 79 & 63.3 \\
\hline
\end{tabular}

\section{Water vapour permeability and resistance to evapo- rative heat loss (Permetest)}

The water vapour permeability (WVP) and resistance to evaporative heat loss results are given in Table 4 . The water vapour permeability values of the treated fabrics were found to be higher than the untreated fabrics. This may be associated with the decrease in the absorbency of the fabrics. The evidence from this study suggests that the PLA reinforcement increases the single-fibre CMC fabric's WVP value, while the HPES fibres reinforcement significantly decreases the CMC fabric's WVP value.

Table 3 Thermal absorptivity (b) properties of treated fabrics

\begin{tabular}{llll}
\hline Fabrics & Dry & Wet & $\begin{array}{l}\text { \% loss in } \\
\text { warmth- } \\
\text { to-touch } \\
\text { feeling }\end{array}$ \\
& $\left(\mathbf{W s}^{1 / 2} \mathbf{~ m}^{-2} \mathbf{K}^{-1}\right)$ & $\left.\mathbf{W}^{1} / \mathbf{2} \mathbf{~ m}^{-2} \mathbf{K}^{-1}\right)$ \\
\hline 100\% CMC untreated & 54 & 60 & 11.1 \\
100\% CMC 0.5\%VC & 40 & 52 & 30 \\
100\% CMC 3\%VC & 47 & 64 & 36.2 \\
100\% CMC 0.5\% ZnO & 38 & 28 & 26.1 \\
100\% CMC 3\% ZnO & 48 & 67 & 39.6 \\
$75 / 25 \%$ CMC/PLA untreated & 49 & 78 & 59.2 \\
$75 / 25 \%$ CMC/PLA 0.5\%VC & 40 & 183 & 357.5 \\
$75 / 25 \%$ CMC/PLA 3\%VC & 54 & 241 & 346.3 \\
$75 / 25 \%$ CMC/PLA 0.5\% ZnO & 47 & 150 & 219.1 \\
$75 / 25 \%$ CMC/PLA 3\% ZnO & 42 & 142 & 238.1 \\
$75 / 25 \%$ CMC/HPES untreated & 43 & 46 & 7 \\
$75 / 25 \%$ CMC/HPES 0.5\%VC & 40 & 60 & 50 \\
$75 / 25 \%$ CMC/HPES 3\%VC & 36 & 47 & 30.6 \\
$75 / 25 \%$ CMC/HPES 0.5\% ZnO & 37 & 42 & 13.5 \\
$75 / 25 \%$ CMC/HPES 3\% ZnO & 39 & 45 & 15.4 \\
\hline
\end{tabular}

Table 4 Thermal conductivity and Permatest results of treated fabrics

\begin{tabular}{|c|c|c|c|c|}
\hline Fabrics & $\begin{array}{l}\text { Dry } \\
\left(\mathrm{W} / \mathrm{mK} \times 10^{-3}\right)\end{array}$ & $\begin{array}{l}\text { Wet } \\
\left(\mathrm{W} / \mathrm{mK} \times 10^{-3}\right)\end{array}$ & $\begin{array}{l}\text { Water vapour } \\
\text { permeability (\%) }\end{array}$ & $\begin{array}{l}\text { Resistance to } \\
\text { evaporative heat loss } \\
\left(\mathrm{m}^{2} \mathrm{~Pa} W^{-1}\right)\end{array}$ \\
\hline $100 \%$ CMC untreated & 33.8 & 39 & 30.2 & 11.8 \\
\hline $100 \%$ CMC $0.5 \%$ VC & 33.2 & 43.9 & 34.5 & 12.1 \\
\hline $100 \%$ CMC 3\%VC & 32.8 & 57 & 32.6 & 11.7 \\
\hline $100 \%$ CMC $0.5 \% \mathrm{ZnO}$ & 32.6 & 35.1 & 29.4 & 13.6 \\
\hline $100 \%$ CMC $3 \% \mathrm{ZnO}$ & 32.2 & 48.5 & 33.9 & 11.8 \\
\hline 75/25\% CMC/PLA untreated & 32.1 & 40.3 & 36.8 & 9.9 \\
\hline 75/25\% CMC/PLA 0.5\%VC & 31.1 & 41 & 37.7 & 9.2 \\
\hline 75/25\% CMC/PLA 3\%VC & 31 & 48.7 & 36.7 & 9.8 \\
\hline 75/25\% CMC/PLA 0.5\% ZnO & 32.4 & 35.4 & 40.8 & 12.7 \\
\hline
\end{tabular}


Table Continued..

\begin{tabular}{lllll}
\hline Fabrics & $\begin{array}{l}\text { Dry } \\
\left(\mathbf{W} / \mathbf{m K} \times 1 \mathbf{0}^{-3}\right)\end{array}$ & $\begin{array}{l}\text { Wet } \\
\left(\mathbf{W} / \mathbf{m K} \times 1 \mathbf{0}^{-3}\right)\end{array}$ & $\begin{array}{l}\text { Water vapour } \\
\text { permeability (\%) }\end{array}$ & $\begin{array}{l}\text { Resistance to } \\
\text { evaporative heat loss } \\
\left(\mathbf{m}^{2} \mathbf{P a W}^{-1}\right)\end{array}$ \\
\hline $75 / 25 \%$ CMC/PLA 3\% ZnO & 31 & 36.1 & 42 & 8.7 \\
$75 / 25 \%$ CMC/HPES untreated & 35.1 & 42.6 & 26.7 & 13.7 \\
$75 / 25 \%$ CMC/HPES 0.5\%VC & 29.7 & 51.6 & 39.5 & 8.8 \\
$75 / 25 \%$ CMC/HPES 3\%VC & 30.6 & 31.7 & 38.2 & 9.3 \\
$75 / 25 \%$ CMC/HPES 0.5\% ZnO & 31.8 & 32.1 & 33.3 & 11.2 \\
$75 / 25 \%$ CMC/HPES 3\% ZnO & 31.7 & 34.1 & 35.6 & 9.9 \\
\hline
\end{tabular}

\section{Conclusion}

The findings of this study suggest that the flexural rigidity properties of CMC dressings can be enhanced by using PLA reinforcement. The thermo physiological comfort properties of the dressings vary and depend largely on the types of fibres present within the wound dressing structure.

\section{Acknowledgements}

None.

\section{Conflict of interest}

Author declares there is no conflict of interest in publishing the article.

\section{References}

1. Pereira S, Anand SC, Rajendran S, et al. A Study of the Structure and Properties of Novel Fabrics for Knee Braces. J Industrial Textiles. 2007;36(4):279-300.

2. Ajmeri JR, Ajmeri CJ. Nonwoven materials and technologies for medical applications. Handbook of medical textiles. Cambridge: Woodhead Publishing; 2011.

3. Liu X, Lin T, Fang J, et al. In vivo wound healing and antibacterial performance of electrospun nano fibre membranes. J Biomed Mater Res A. 2010;94(2):499-508. 